\title{
Effects of Ascorbic Acid and Phenolic Content Concentrations on Natural Reduction of Silver Ions from Plant Extracts
}

\author{
Shruti Tyagi* \\ Women Scientist-A (WOS-A), DST, Department of Biotechnology, Meerut Institute of \\ Engineering and Technology, Meerut, Uttar Pradesh, India \\ *Corresponding author
}

\section{A B S T R A C T}

\section{Keywords}

Silver nanoparticles; ascorbic acid; phenolic contents; chenopodium extract; marigold extract.

\section{Article Info}

Accepted:

20 October 2016

Available Online:

10 November 2016
In the present research silver nanoparticles was produced by naturally reduction of silver ions from plant extracts by using silver nitrate as a precursor and investigate the effects of phytochemical, ascorbic acid and total phenolic content on reduction of silver ions from plant materials. In the presence of ascorbic acid concentration $38.88 \mu \mathrm{g} / \mathrm{gm}$ and $35.5088 \mu \mathrm{g} / \mathrm{gm}$ and the phenolic contents concentration $97.89 \mu \mathrm{g} / \mathrm{gm}$ and $26.99 \mu \mathrm{g} / \mathrm{gm}$ in Chenopodium and Marigold extracts respectively the multiple plasmon peaks were observed at the range of $360-426 \mathrm{~nm}$ with absorbance of $0.780-0.925 \mathrm{~cm}^{-1}$ in chenopodium extract with absorbance 0.392 $0.569 \mathrm{~cm}^{-1}$ in marigold extract. The appearance of multiple surface plasmon peaks indicated the spherical shape of silver nanoparticles. Obtained multiple plasmon resonances at 360-426nm and 310-450nm in Chenopodium and Marigold extracts, respectively may be indication of maximum reduction of $\mathrm{Ag}^{+}$ions and this enhancement of maximum reduction of $\mathrm{Ag}^{+}$ions due to the presence of ascorbic acid and total phenolic content higher concentrations.

\section{Introduction}

Biosynthesis of nanoparticles using plant extract is a cost-effective approach because the preparation of plant extract normally utilized biomass wastes such as leaves, flowers, roots, fruit peels, etc. These parts of plant can be used either fresh or dried. But the dry form is more preferable due to differences in water content within different plant tissues (Tiwari et al., 2011). Nanotechnology and nanofabrication has opened its doors to a world of metal nanoparticles synthesis with easy preparation protocols, less toxicity and a wide range of applications according to their size and shape (Pankaj et al., 2012). The dried plant was normally ground into fine powder while the fresh one was chopped into small pieces. Controllability in biological methods is far easier to achieve than with other methods (Tyagi, 2016). This size reduction step facilitated in increasing the extraction rate due to increased surface area. Extraction process is possible whether by utilizing polar or non-polar solvents. After sufficient extraction time, the mixture was filtered and the filtrate was further use in synthesis of nanoparticle. In recent years, noble metal nanoparticles have been the 
subject of focused research due to their unique optical, electronic, mechanical, magnetic and chemical properties that are significantly different from those of bulk materials. Silver nanoparticles play a profound role in the field of biology and medicines due to their attractive physiochemical properties. There has been intense interest recently among the public and the media in the possibility that increased intake of dietary antioxidants may protect against chronic diseases, which include cancers, cardiovascular, and cerebrovascular diseases. Antioxidants are substances that, when present at low concentrations, compared with those of an oxidizable substrate, significantly prevent or delay a pro-oxidant-initiated oxidation of the substrate (Prior \&Cao, 1999). A prooxidant is a toxic substance that can cause oxidative damage to lipids, proteins, and nucleic acids, resulting in various pathological events or diseases. The synthesis of metallic nanoparticles can be done by reducing metal ion using some chemical molecules. Plants contain an ample of free radical scavenging molecules such as phenolic compounds, nitrogen compounds, vitamins, reducing sugar, terpenoids and some other metabolites that are rich in antioxidant activity. The plants used to synthesize nanoparticles are known to be rich in polyols and antioxidant. The hydroxyl and carboxylic group present in plants may act as reducing agent and stabilizing agents in the synthesis of nanoparticles (Vilchis-Nestor et al., 2008). Song, Jang and Kim (Song et al., 2009) reported that for the $\mathrm{M}$. Kobus extract, the proteins and terpenoids are believed to act as reducing agent. According to Amin, Anwar, Janjua, Iqbal and Rashid (Amin et al., 2012), functional groups such as phenolics and alkaloids are responsible for capping and stabilizing of nanoparticles reduced. The reduction mechanism also capable to control the size and stability of the nanostructured produced. The stability of nanoparticles can attributed to the formation of stable bonding between metallic nanoparticles and phytochemicals present in the leaf extract (Kanchana et al., 2010).

Nanoparticles can modify the physicochemical properties of the material as well as create the opportunity for increased uptake and interaction with biological tissues. This combination of effects can generate adverse biological effects in living cells that would not otherwise be possible with the same material in larger form. Nanoparticles have the ability to cross biological membranes and access the cells, tissues and organs through inhalation or ingestion. The toxicological studies indicates that toxicity percentage inhabitation of $\mathrm{CH}-\mathrm{AgNPs}$ was much greater than the Bio-AgNPs synthesized from apple onion, garlic and followed by papaya and observed PI value indicated that the gut microbial community probiotic $B$. subtilis and $E$. coli was killed in higher percentage of $\mathrm{CH}-\mathrm{AgNPs}$ as compare to Bio-AgNPs synthesized from apple, onion garlic and papaya (Tyagi et al., 2013, 2016). Bio-AgNPs is the most suitable metallic coating material coat to drugs instead of $\mathrm{CH}-\mathrm{AgNPs}$ in pharmaceutical industries (Tyagi et al., 2013).

\section{Materials and Methods}

\section{Preparation of sample extracts}

$10 \mathrm{gm}$ of Chenopodium leaves and Marigold leaves were taken and thoroughly washed in distilled water. Washed leaves crushed with motor pestle and then mixed into sterile deionize water after that it was boiled for around 10min. Extract of samples were filtered through whatman filter paper (Pore size $45 \mu \mathrm{m}$ ) and centrifuged for $10 \mathrm{~min}$ at 
4000 RPM. The aforementioned extracts were used immediately for biosynthesis of silver nanoparticles.

\section{Synthesis of silver ions}

$10 \mathrm{~mL}$ of the leaf extract was added drop by drop into $90 \mathrm{~mL}$ of aqueous solution of $1 \mathrm{mM}$ $\mathrm{AgNO}_{3}$ for reduction into $\mathrm{Ag}^{+}$ion. It was done on magnetic stirrer at $50-60^{\circ} \mathrm{C}$ temperature. The formations of AgNPs are confirmed by color changing from light green to dark brown/black and primary confirmation of $\mathrm{Ag}+$ ion via UV-VIS spectrophotometer was confirmed. Prepared brown/black AgNPs samples were stored at room for $48-70 \mathrm{hr}$.

\section{Determination of ascorbic acid}

Determination of ascorbic acid was done using UV-VIS spectrophotometer. Ascorbic acid content was determined using 2, 6 dichlorophenol-indophenol spectrophotometric method (Horwitz 1980).

\section{Determination total phenolic contents}

A total phenolic content were determined by Folin-Ciocalteau reagent in an alkaline medium and was expressed as gallic acid equivalents.

\section{Results and Discussion}

In this study AgNPs were synthesized from Chenopodium and Marigold which are easily available and have medicinal importance from ancient times. Bioreduction is main phenomenon which is responsible for the NPs synthesis. Extracts prepared from these plants have good amount of various kind of sugar, proteins, vitamins, ascorbic acid and phenolic substances. Previous studies indicated that various kind of reducing agents present in the plant extract which provide as chance to synthesis ecofreindly and less toxic way. During the synthesis of AgNPs from chili researchers believed that polyphenols and ascorbic acid might be played significant role in synthesis of AgNPs (Jha and Prasad, 2011).

\section{Determination of ascorbic acid and total phenolic contents concentration}

Ascorbic acid concentration was determined after biosynthesis of AgNPs from samples. Results indicated that ascorbic acid concentration $38.88 \mu \mathrm{g} / \mathrm{gm}$ and $35.5088 \mu \mathrm{g} / \mathrm{gm}$ were observed in Chenopodium and Marigold extracts respectively. On the other hand, the total phenolic contents concentration $97.89 \mu \mathrm{g} / \mathrm{gm}$ and $26.99 \mu \mathrm{g} / \mathrm{gm}$ were found in Chenopodium and Marigold extracts respectively (Table 1). The multiple plasmon peaks were observed at the range of $360-426 \mathrm{~nm}$ with absorbance range of 0.780$0.925 \mathrm{~cm}^{-1}$ in Chenopodium extract and $310-450 \mathrm{~nm}$ with absorbance range 0.392$0.569 \mathrm{~cm}^{-1}$ in marigold extract. As shown in figure 1, the appearance of the wide range in absorptions and UV-visible nanometer scale indicated to enhancement of $\mathrm{Ag}^{+}$reduction (found multiple plasmon peaks) in the reaction mixture of both Chenopodium and Marigold extracts. Obtained results, indicated that the phytochemical ascorbic acid and total phenolic contents concentrations present in the plant extracts enhance the reduction of $\mathrm{Ag}^{+}$ions in reaction mixture. We observed at the time of measuring the concentration of some samples at UV-VIS spectrophotometer the variation in concentration $(\mu \mathrm{g} / \mathrm{gm})$ of phytochemicals (ascorbic acid and total phenolic contents) were found. Those samples contain minimum concentration of ascorbic acid and total phenolic contents no plasmon resonance was observed the curved single peak. 
Table.1 Phytochemicals ascorbic acid and total phenolic concentration $(\mu \mathrm{g} / \mathrm{gm})$ in Marigold and Chenopodium extract

\begin{tabular}{|c|c|c|c|}
\hline S. No. & Phytochemicals & $\begin{array}{c}\text { Marigold extract } \\
\text { Concentration }(\boldsymbol{\mu g} / \mathbf{g m})\end{array}$ & $\begin{array}{c}\text { Chenopodium extract } \\
\text { Concentration }(\boldsymbol{\mu g} / \mathbf{g m})\end{array}$ \\
\hline 1 & Ascorbic acid & 35.46 & 38.88 \\
\hline 2 & Phenolic contents & 97.89 & 26.99 \\
\hline
\end{tabular}

Fig.1a UV-spectrum of AgNPs synthesized from marigold extract

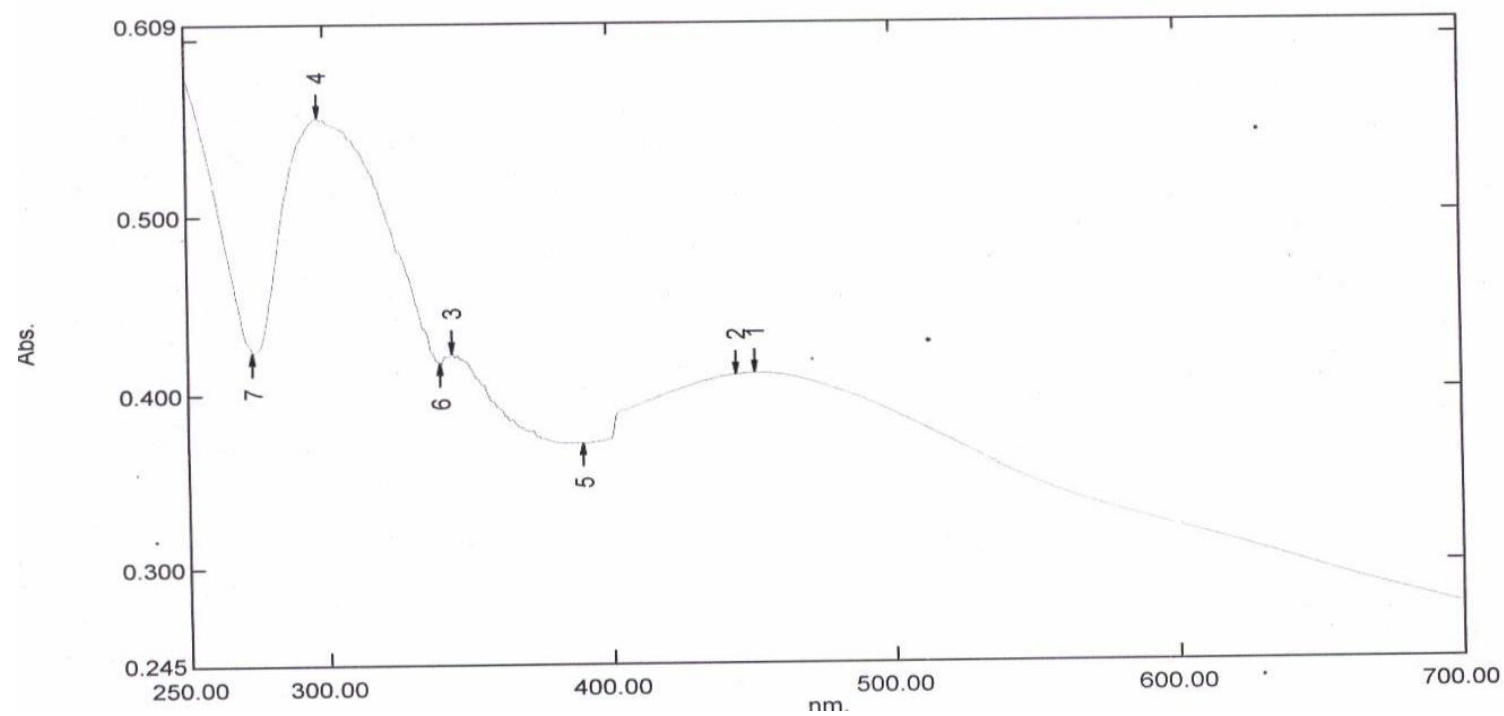

Fig.1b UV-spectrum of AgNPs synthesized from chenopodium extract

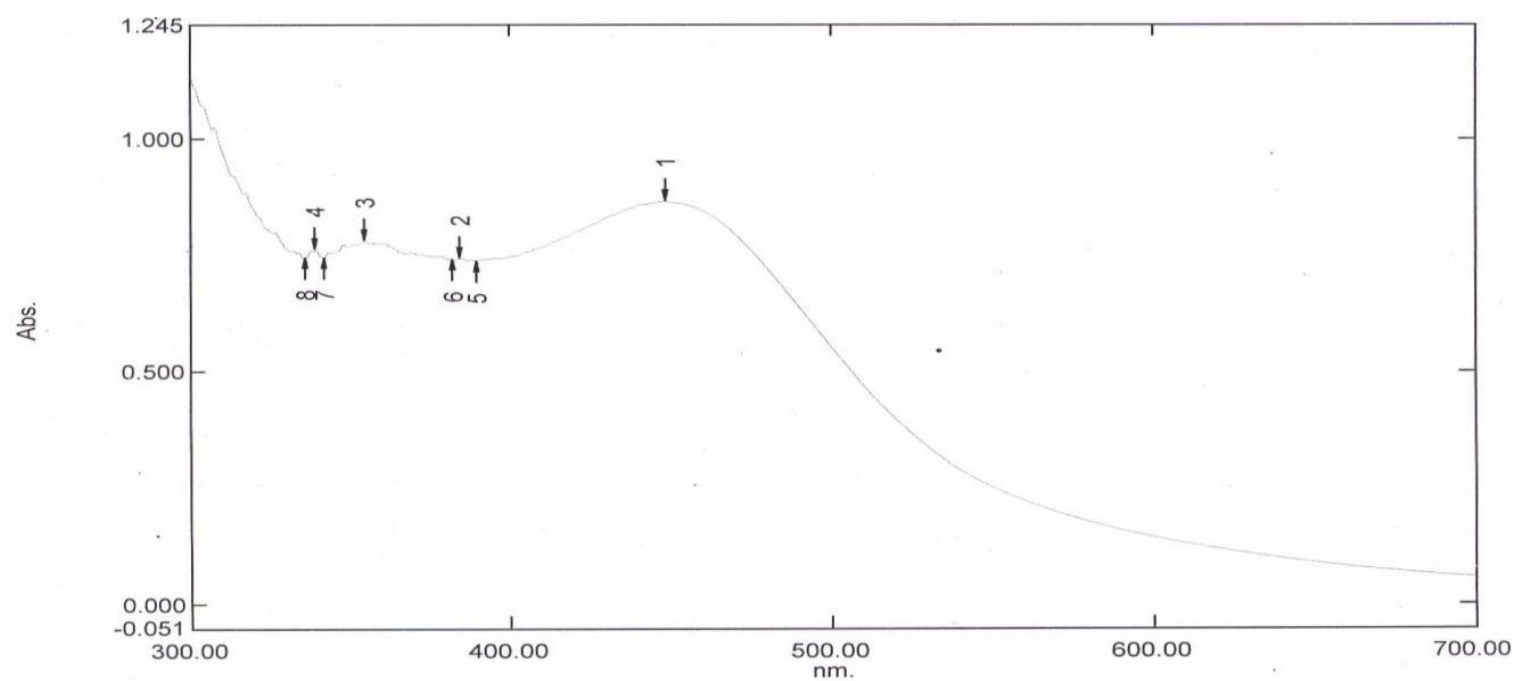


Fig.2 Determination of ascorbic acid and total phenolic concentration $(\mu \mathrm{g} / \mathrm{gm})$ in marigold and chenopodium extract after synthesis of AgNPs

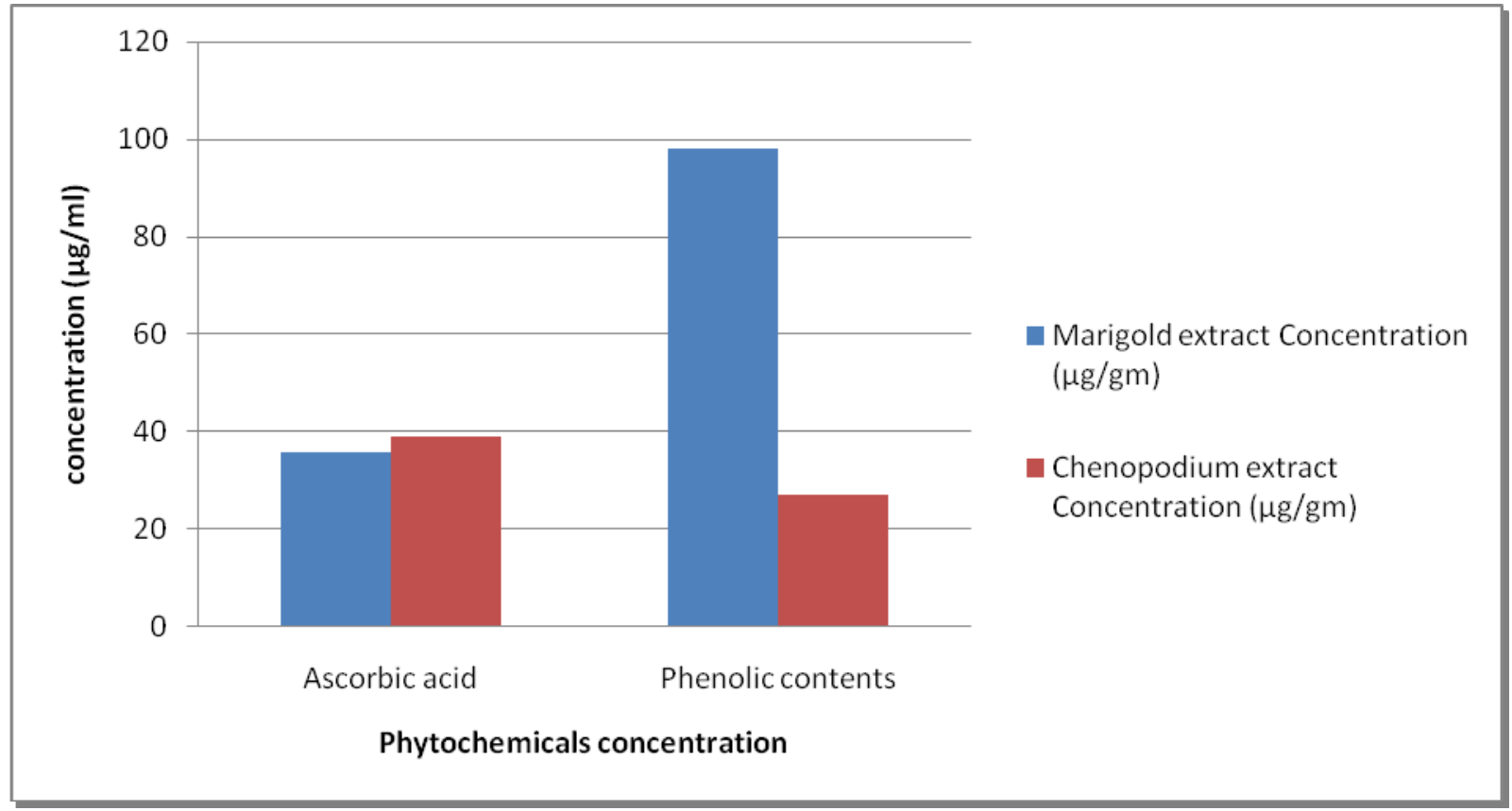

Samples which have maximum concentration of ascorbic acid and total phenolic contents a multiple plasmon resonance observed. Some samples are not following this observation so it may be further investigation. On the other hand, the multiple surface plasmon peaks representing the shape of the particles and here this indicated the spherical shape of AgNPs (primary characterization). As shown in figure 2, multiple plasmon resonances were found to enhance the absorption in the presence of ascorbic acid and total phenolic content concentration over a broad wavelength range. In previous data some researchers indicated that ascorbic acid is main factor which responsible for biosynthesis of silver nanoparticles (Caroling et al., 2013). It is proven in various studies that biochemical in plant leaves play significant role in reduction of ionic salts. Bioreduction is understood as main cause by which nanoparticles are synthesizes. There are various kind of reductants used for chemical synthesis of nanoparticles (Tyagi et al., 2013). Chemical reductants are costly and toxic some of them may produce toxic byproducts.

\section{Acknowledgements}

This work was supported in part by a grant from the Department of Science and Technology under the Women Scientist Scheme-A (WOS-A) project no SR/WOSA/LS-1171/2014 government of INDIA.

\section{References}

Amin, M., F. Anwar, M.R. Janjua, M.A. Iqbal, U. Rashid. 2012. Green synthesis of silver nanoparticles through reduction with Solanum xanthocarpum L. berry extract: characterization, antimicrobial and urease inhibitory activities against Helicobacter pylori, Int. J. Mol. Sci., 13: 9923-9941.

Caroling, G., Tiwari, S.K., Ranjitham, A.M., Suja, R. 2013. Biosynthetic and silver 
nanoparticles using aques borocolli extracts- characterization and study of antimicrobial cyrtotoxic effect. Asian $J$. Pharm. Clin. Res., 6(4): 165-172.

Horwitz, W. 1980. "Official method of analysis of the official analytical chemists," 13th ed, Association of official analytical chemists, Washington DC 476.

Jha, A.K. and Prasad, K. 2011. green fruit of chili (Capsicum annum L.) synthesizes nano silver. Digest J. Nanomaterials and Biostructures, 6(4): 1717-1723.

Kanchana, A., S. Devarajan, S. Rathakrishnan Ayyappan. 2010. Green synthesis and characterization of palladium nanoparticles and its conjugates from Solanum trilobatum leaf extract, Nano-Micro Lett., 2:169-176.

Pankaj, K., Tyagi, Shruti Tyagi, Charul Verma, Aanchal Rajpal. 2013. Estimation of toxic effects of chemically and biologically synthesized silver nanoparticles on human gut microflora containing Bacillus subtilis, J. Toxicol. Environ. Health Sci., 5(9): 172-177.

Pankaj, K., Tyagi, Shruti Tyagi, Sudhir Singh and Harish Sharma. 2013. Estimation of silver nanoparticles toxicity on human gut micro flora. Int. J. Develop. Res., 3(9): 027-030.

Pankaj, K., Tyagi. 2016. Production of Metal Nanoparticles from Biological Resources, Int. J. Curr. Microbiol. App. Sci, 5(3): 548-558.

Prior, R.L., Cao, G. 1999. In vivo total antioxidant capacity: comparison of different analytical methods. Free Rad.
Biol. Med., 27: 1173-1181.

Song, J.Y., H.K. Jang, B.S. Kim. 2009. Biological synthesis of gold nanoparticles using Magnolia kobus and Diopyros kaki leaf extracts, Process Biochem., 44: 1133-1138.

Tiwari, P., B. Kumar, M. Kaur, G. Kaur, H. Kaur. 2011. Phytochemical screening and extraction: A review, Internationale Pharmaceutica Sciencia, 1: 98-106.

Tyagi, P.K., M. Mishra, N. Khan, S. Tyagi, S. Sirohi. 2016. Toxicological study of silver nanoparticles on gut microbial community probiotic. Environ. Nanotechnol. Monitoring \& Management, 5: 36-43.

Tyagi, P.K., Shruti, V., Sarsar, A., Anami, 2012. Synthesis of Metal Nanoparticals: A Biological Prospective for Analysis, Int. J. Pharmaceutical Innovations, 2(4): 48-60.

Tyagi, P.K., Tyagi, S., Verma, C. and Rajpal, A. 2013. Estimation of toxic effects of chemically and biologically synthesized silver nanoparticles on human gut microflora containing Bacillus subtilis. J. Toxicol. Env. Health Sci., 5(9): 172-177.

Vilchis-Nestor, A.R., V. Sanchez-Mendieta, M.A. Camacho-López, R.M. Gómezspinosa, M.A. Camacho-López, J.A. Arenas-Alatorre 2008. Solventless synthesis and optical properties of $\mathrm{Au}$ and Ag nanoparticles using Camellia sinensis extract, Materials Lett., 62:3103- 3105 .

\section{How to cite this article:}

Shruti Tyagi. 2016. Effects of Ascorbic Acid and Phenolic Content Concentrations on Natural Reduction of Silver Ions from Plant Extracts. Int.J.Curr.Microbiol.App.Sci. 5(11): 885-890. doi: http://dx.doi.org/10.20546/ijcmas.2016.511.101 